\title{
Utility of calcium, magnesium and phosphate testing in the emergency department
}

\section{(Calcium, Magnesium and Phosphate testing)}

Patrick A Date BSci MD ${ }^{1}$

patrick.a.date@gmail.com

Jesse L Smith BSci MD²

jesse.lachlan.smith@gmail.com

William S Spencer BMedSci MD 3

Willsspencer1@gmail.com

Erik J de Tonnerre BMedSci MD ${ }^{4}$

edetonnerre@gmail.com

Michael J Yeoh MBBS FACEM ${ }^{5}$

Michael.Yeoh@austin.org.au

David McD Taylor MD DRCOG MPH FACEM ${ }^{6,7}$

David.Taylor@austin.org.au

${ }^{1}$ Intern, Austin Hospital, Studley Road, Heidelberg, Victoria, Australia

${ }^{2}$ Intern, Central Gippsland Health, Sale, Victoria, Australia

${ }^{3}$ Intern, Alfred Health, Commercial Road, Melbourne, Victoria, Australia

${ }^{4}$ Intern, Northern Sydney Local Health District, NSW Health, NSW

${ }^{5}$ Staff Specialist, Emergency Department, Austin Hospital, Studley Road, Heidelberg, Victoria, Australia

${ }^{6}$ Director of Emergency Medicine, Emergency Department, Austin Hospital, Studley Road, Heidelberg, Victoria, Australia

${ }^{7}$ Professor, Department of Medicine, University of Melbourne, Parkville, Victoria, Australia

\section{Corresponding Author:}

Professor David Taylor

Emergency Department, Austin Hospital

Studley Road, Heidelberg, Victoria, Australia 3084

Phone (W) +61 394964711

David.Taylor@austin.org.au

\section{Author Contributions:}

This is the author manuscript accepted for publication and has undergone full peer review but has not been through the copyediting, typesetting, pagination and proofreading process, which may lead to differences between this version and the Version of Record. Please cite this article as doi: 10.1111/1742-6723.13332

This article is protected by copyright. All rights reserved. 
PD, MY and DT developed the protocol for the project that this research was drawn from. DT obtained ethics committee approval. PD, JS, WS and EdeT collected all the data. All authors assisted DT in data analysis and interpretation. All authors contributed to drafting and critical revision of the manuscript. DT supervised the project overall. All authors take responsibility for the manuscript.

Word count: 2500

\begin{abstract}
Objective

To determine how frequently calcium $(\mathrm{Ca})$, magnesium $(\mathrm{Mg})$ and phosphate $\left(\mathrm{PO}_{4}\right)$ tests change emergency department (ED) patient management
\end{abstract}

\title{
Methods
}

We undertook a retrospective observational study in an Australian tertiary referral ED. We enrolled adult patients (aged e 18 years) who presented between January-June 2017 and who had a serum $\mathrm{Ca}, \mathrm{Mg}$ or $\mathrm{PO}_{4}$ test ordered and completed during their ED stay. Patient symptoms, medical history, electrolyte levels, and ED management changes were extracted from the electronic medical record.

\section{Results}

33,120 adults presented during the study period. $1,716(5.2 \%, 95 \%$ CI $5.0,5.4)$ had at least one $\mathrm{Ca}, \mathrm{Mg}$ or $\mathrm{PO}_{4}$ test completed in the ED. This included 4,776 individual electrolyte tests, of which $776(16.2 \%, 95 \%$ CI 15.2, 17.3) were abnormal. 56 tests were associated with a change in ED management $(7.2 \%$ [95\%CI 5.5, 9.3] of patients with abnormal tests, $1.2 \%$ [95\%CI $0.9,1.5]$ of all tests). 26/1,683 (1.5\%) Ca levels were low with six (23.1\%) management changes; 203 (12.1\%) were high with ten (4.9\%) management changes.

This article is protected by copyright. All rights reserved. 
128/1,579 (8.1\%) Mg levels were low with 33 (25.8\%) management changes; 30 (1.9\%) were high with no management changes. 225/1,514 (14.9\%) $\mathrm{PO}_{4}$ levels were low with six (2.7\%) management changes; $164(10.8 \%)$ were high with one $(0.6 \%)$ management change. $50(2.9 \%)$ patients had management changes despite normal electrolyte levels.

\section{Conclusion}

$\mathrm{Ca}, \mathrm{Mg}$ and $\mathrm{PO}_{4}$ testing is common. However, the yield of clinically significant abnormal levels is low and patient management is rarely changed. Testing of these electrolytes needs to be rationalised.

Keywords: Calcium, Magnesium, Phosphate, Utility, Emergency Health Service, Choosing Wisely

This article is protected by copyright. All rights reserved. 


\section{INTRODUCTION}

Recently, health services worldwide have focused on the reduction of unnecessary laboratory and imaging investigations. One such approach has been the Choosing Wisely initiative. ${ }^{1}$ Launched in 2012, Choosing Wisely has become a worldwide movement towards improving patient care and minimising spending on tests and treatments that provide minimal or no patient benefit. ${ }^{1,2}$ Laboratory tests have been a particular focus of the Choosing Wisely recommendations. These have included, among others, the testing of coagulation, blood cultures and prostate specific antigen where not indicated by evidence. , $^{3,4}$

In the emergency department (ED) setting, the usefulness of calcium $(\mathrm{Ca})$, magnesium $(\mathrm{Mg})$ and phosphate $\left(\mathrm{PO}_{4}\right)$ testing has been questioned. In 1997, Rose et al. ${ }^{5}$ reported that these tests have a low yield of abnormal results and are of limited usefulness. They recommended reductions in their ordering in order to reduce investigation costs. Since this early study, however, there have been no other reports of the utility of these electrolyte tests in the ED.

Anecdotally, $\mathrm{Ca}, \mathrm{Mg}$ and $\mathrm{PO}_{4}$ tests are commonly ordered. However, the extent and cost of testing, the yield of abnormal results and, importantly, the impact on ED management are not known. We aimed to assess the utility of these tests in the ED. The findings will inform the development of clinical guidelines for the rational ordering of these tests.

This article is protected by copyright. All rights reserved. 


\section{METHODS}

We undertook a retrospective, observational study of patients in the ED of a tertiary referral hospital in Melbourne, Australia. The ED has a mixed (paediatric and adult) annual census of approximately 90,000 patients. Approval to undertake the study was granted by the institution's Human Research Ethics Committee.

Adult patients (aged e 18 years) who presented between January 1 and June 30, 2017 (inclusive) were included if they had a $\mathrm{Ca}, \mathrm{Mg}$ and/or $\mathrm{PO}_{4}$ test ordered and completed (results available) during their ED stay. There were no exclusion criteria. Suitable patients were identified electronically using Cerner FirstNet ${ }^{\circledR}$ (version 2015.01.17, Cerner Corporation, North Kansas City, Missouri, USA).

The electronic medical records of included patients were accessed by the principal investigator (PD) and explicit data extraction was undertaken using a data collection document designed for the study. Data included age, gender, date of presentation, Australasian Triage Category, presenting complaint, corrected $\mathrm{Ca}, \mathrm{Mg}$ and $\mathrm{PO}_{4}$ levels, and ED management change. The data of $5 \%$ of patients was double-checked by a second investigator and no inconsistencies were found.

Management change included any standard electrolyte correction treatment(s) administered in the context of either a low or high level of one or more of the electrolytes e.g. IV Mg administered in the context of a low Mg level. A standard treatment administered in the 
context of a normal electrolyte level was not considered a management change as a result of the test. In these circumstances, the treatment may have been administered for other clinical indications (e.g. IV normal saline for hypotension). We only examined ED patient management. Management in the inpatient setting, based upon ED electrolyte levels, was not examined.

Patients were only included if their electrolyte tests had been completed before their discharge from the ED and, therefore, the results were available to inform ED management. For patients admitted to the hospital, this was determined by comparison of unique timestamps for the tests and the recorded time of ED discharge. Patients who were discharged home or to the short stay unit were assumed to have had their test completed during their ED stay.

The primary study outcome was a change of ED management in the context of any abnormal $\mathrm{Ca}, \mathrm{Mg}$ or $\mathrm{PO}_{4}$ level. Secondary outcomes included the frequency of testing of these electrolytes, the yield of abnormal results and the costs involved.

The hospital's standard reference ranges for each electrolyte test were obtained from the institution's pathology department. All tests employed colourimetric assay (Ca: NMBAPTA, Mg: Xylidyl blue, $\mathrm{PO}_{4}$ : ammonium molybdite) on an automated track system. Instruments and reagents were sourced from Roche Diagnostics (Ryde, New South Wales, Australia).

This article is protected by copyright. All rights reserved. 
The total cost of the $\mathrm{Ca}, \mathrm{Mg}$ and $\mathrm{PO}_{4}$ tests at our institution was best estimated using the Medicare Benefits Schedule. ${ }^{6}$ If a single $\mathrm{Ca}, \mathrm{Mg}$ or $\mathrm{PO}_{4}$ test is ordered, AUD\$9.70 is charged to taxpayers. If two or three tests are ordered the charges are AUD\$11.65 and AUD\$13.65.

Rose et al. ${ }^{5}$ reported that $5.2 \%$ of their ED patient population had a $\mathrm{Ca}, \mathrm{Mg}$ or $\mathrm{PO}_{4}$ test. In order to have a $95 \%$ chance that our proportion would lie $\pm 1.0 \%$ of Rose's proportion (i.e. 4.2-6.2\%) we needed to enrol at least 1972 patients. However, due to methodological differences (definition of abnormal electrolyte levels), it was not possible to calculate a sample size based upon yield of abnormal results or management change. Given this, we elected for a long study period in order to achieve a sample size likely to be well in excess of that required for an adequate descriptive study.

Descriptive statistics were employed to analyse all data e.g. mean (standard deviation) and percentage (95\%confidence interval). All analyses were undertaken using SPSS for Windows statistical software (version 24.0, SPSS Inc., Chicago, Illinois, USA).

This article is protected by copyright. All rights reserved. 


\section{RESULTS}

Of the 33,120 adult patients who presented during the study period, $1,716(5.2 \%, 95 \% \mathrm{CI} 5.0$, 5.4) met the study inclusion criteria (Figure 1). The mean (SD) patient age was 64 (20.1) years and $810(47.2 \%, 95 \%$ CI $44.8,49.6)$ patients were male.

A total of 4,776 individual $\mathrm{Ca}, \mathrm{Mg}$ and $\mathrm{PO}_{4}$ tests completed while the patients were in the ED: $1,683\left(5.1 \%\right.$ of patients) $\mathrm{Ca}, 1,579(5.8 \%) \mathrm{Mg}$ and 1,514 (4.6\%) $\mathrm{PO}_{4}$ tests. All three electrolytes were ordered together on 1,505 (87.7\%) occasions, two electrolytes on 50 (2.9\%) occasions, and a single electrolyte on $161(9.4 \%)$ occasions.

Of those that had $\mathrm{Ca} / \mathrm{Mg} / \mathrm{PO} 4$ testing, 624 (36.4\%) patients had at least one $\mathrm{Ca}, \mathrm{Mg}$ or $\mathrm{PO}_{4}$ level outside the reference range (Figures 2-4). There were $776(16.2 \%)$ abnormal levels in total. Relative to their respective total test number, these included $229(13.6 \%) \mathrm{Ca}, 158$ (10.0\%) Mg and 389 (25.7\%) $\mathrm{PO}_{4}$ abnormalities.

Emergency department management was changed for $51(3.0 \%)$ patients tested. There were $57(1.2 \%)$ individual tests that lead to management changes. 65 management changes were noted in total. Of the 211 cases where specific electrolytes were targeted (only one or two tested), 41 (19.4\%) abnormalities were found but only five patients were treated.

$203(12.1 \%)$ patients had hypercalcaemia (Figure 2). 10 (4.9\%) of those patients were treated with 16 individual treatments. The majority received IV fluid, whilst some 
additionally received bisphosphonates, frusemide or calcitonin. $26(1.5 \%)$ patients had hypocalcaemia. Six (23.1\%) patients were treated with nine individual treatments. All received IV $\mathrm{Ca}$ and half additionally received oral $\mathrm{Ca}$. In total, $16(1.0 \%)$ patients were treated because of their $\mathrm{Ca}$ result. One $(0.1 \%)$ patient received IV Ca because of a low ionised Ca result, despite a normal serum Ca result.

$30(1.9 \%)$ patients had hypermagnesaemia although none was treated (Figure 3). 128 (8.1\%) patients had hypomagnesaemia and $33(25.8 \%)$ were treated with 33 individual treatments. The majority of patients received IV $\mathrm{Mg}$, with a smaller proportion receiving oral $\mathrm{Mg}$. Of those patients with a $\mathrm{Mg}$ level within the reference range, 49 (3.4\%) were administered $\mathrm{Mg}$. The diagnoses of these 49 patients included atrial fibrillation (31 patients), ventricular tachycardia (5), ventricular bigeminy (2), supraventricular tachycardia (2), and one case of the following: asthma, hypokalaemic ECG changes, premature ventricular beats, bradycardia, decreased oral intake, dehydration, delirium, diarrhoea and intussusception.

$164(10.8 \%)$ patients had hyperphosphataemia although only one $(0.6 \%)$ was treated (Figure 4). $225(14.9 \%)$ patients had hypophosphataemia and six (2.7\%) were treated with six individual treatments. The majority received oral $\mathrm{PO}_{4}$ replacement, however one patient received IV $\mathrm{PO}_{4}$. In total, seven $(0.5 \%)$ patients were treated because of their $\mathrm{PO}_{4}$ result.

For the six-month study period, all $\mathrm{Ca}, \mathrm{Mg}$ and $\mathrm{PO}_{4}$ tests cost $\mathrm{AUD} \$ 22,687.45$. The cost of those tests directly changing patient management in the ED was AUD\$506.40. Thus, 
AUD $\$ 22,181.05(97.8 \%$ of the total cost) was expended but did not change patient management.

This article is protected by copyright. All rights reserved. 


\section{DISCUSSION}

This study shows that a substantial proportion of adult ED patients (approximately one in 20) have at least one $\mathrm{Ca}, \mathrm{Mg}$ or $\mathrm{PO}_{4}$ test completed in the $\mathrm{ED}$. As the study population comprised all adults, including those with minor problems, the proportion tested among those with complex medical issues is likely to be considerably higher. There is a paucity of literature regarding the utility of $\mathrm{Ca}, \mathrm{Mg}$ and $\mathrm{PO}_{4}$ testing in the $\mathrm{ED}$ and general hospital settings. However, Rose et al. ${ }^{5}$, in a smaller ED study, reported an identical proportion of patients who had $\mathrm{Ca}, \mathrm{Mg}$ and $\mathrm{PO}_{4}$ levels measured. Their study population contained younger patients and more males than we observed.

The yield of abnormal $\mathrm{Ca}, \mathrm{Mg}$ and $\mathrm{PO}_{4}$ levels varied considerably $(13.6 \%, 10.0 \%$ and $25.7 \%$, respectively). Importantly, for each electrolyte, the large majority of abnormal levels were only marginally outside of the respective reference range. Hence, the clinical significance of most of the abnormal levels is questionable. This is supported by the finding that, overall, only small proportions of patients with abnormal levels had a management change. In contrast to our study, Rose et al. ${ }^{5}$ used values $\pm 15 \%$ outside the normal electrolyte ranges as a marker of abnormality. This difference makes it difficult for a direct comparison between our findings and those of Rose et al. ${ }^{5}$.

The very small proportion of patients with abnormal levels and a management change is consistent with that of Rose et al. ${ }^{5}$ who reported a management change in only $0.3 \%$ of 
patients. In both studies, the substantial number of tests performed and the relatively few management changes suggest that testing for these electrolyte levels is excessive.

Low Mg levels were treated more than any other electrolyte abnormality. This may be due to the reported association of hypomagnesaemia with cardiac arrhythmias and neuromuscular instability. ${ }^{7,8}$ However, $\mathrm{Mg}$ was often administered to patients with normal Mg levels. This was most commonly in patients with atrial fibrillation (AF) or flutter. It has been reported that $\mathrm{Mg}$ may have a role in AF prevention in the post-operative cardiothoracic surgery setting. ${ }^{9,10}$ However, there is conflicting evidence regarding the efficacy of $\mathrm{Mg}$ in AF treatment in the ED and other settings. ${ }^{11-14}$ As many of these studies had methodological limitations ${ }^{11,14}$, there is no high-level evidence to support the use of $\mathrm{Mg}$ for the treatment of $\mathrm{AF}$ in the ED. Hence, the rationale for its use in this study is unclear.

Although $\mathrm{PO}_{4}$ levels were more frequently abnormal than $\mathrm{Ca}$ and $\mathrm{Mg}$, management was rarely changed. There is conflicting evidence regarding the association between $\mathrm{PO}_{4}$ levels and patient outcomes. ${ }^{8,15}$ It has been reported that treatment is not necessary unless the levels are very low. ${ }^{7,8,16}$ Given this, and the finding that very few patients had $\mathrm{PO}_{4}$ administered, the place for $\mathrm{PO}_{4}$ testing in the ED is likely to be limited. Interestingly, $\mathrm{PO}_{4}$ was never tested alone and this hints at the possibility that $\mathrm{PO}_{4}$ ordering is a reflex when ordering other electrolytes, especially Ca. 
It is difficult to accurately determine the cost of pathology testing in Australian hospitals. From our best estimates, using the Medicare Benefits Schedule, ${ }^{6}$ our tests would cost $\$ 45,750.90$ annually. As only a very small proportion of tests resulted in management change, it is likely that a substantial cost saving could be achieved if $\mathrm{Ca}, \mathrm{Mg}$ and $\mathrm{PO}_{4}$ testing were better targeted. Rose et al. ${ }^{5}$ reported that $\$ 105,000$ could be saved annually by only testing patient groups that might benefit, as well as adhering to 'non-stat' testing (a less expensive option in their setting). ${ }^{5}$

Our findings indicate that targeting of specific electrolytes resulted in very few management changes. Given the apparent excessive testing for these electrolytes, there is a need for better targeting of patients most at risk of abnormal levels and where correction of the abnormality would be indicated. The most common conditions associated with abnormal levels include older age, diuretic use, malnutrition, cancer, chronic renal disease, diabetes, alcoholism and a wide range of medications. ${ }^{5,16-20}$

Specifically, calcium abnormalities have been associated with thyroid and parathyroid disease, acute pancreatitis, hyperphosphataemia, thyrotoxicosis, granulomatous disease, medications, total parenteral nutrition and immobilization. ${ }^{7,21}$ Magnesium abnormalities have been associated with lithium therapy, thyroid disease, excessive tissue breakdown (e.g. sepsis, large burns), inherited renal tubular defects, hyperaldosteronism and hypoparathyroidism. ${ }^{7,22}$ Phosphate abnormalities have been associated with changes in gastrointestinal absorption or renal excretion, rapid intracellular-to-extracellular shifts and 
vitamin D intoxication. ${ }^{7,23}$ However, these associations have generally been reported from non-ED settings. Well-powered studies are, therefore, recommended to identify ED patient comorbidities, symptomatology and usual medications that place them at greater risk of abnormalities in these electrolytes. ${ }^{7,15}$ Findings from such studies will help inform clinical guidelines to assist in more rational $\mathrm{Ca}, \mathrm{Mg}$ and $\mathrm{PO}_{4}$ testing.

Interventions to reduce $\mathrm{Ca}, \mathrm{Mg}$ and $\mathrm{PO}_{4}$ testing have been reported. ${ }^{5,24-26}$ Rose et al. ${ }^{5}$ recommended that patients with diabetes, chronic renal failure or a history of alcoholism should be targeted. Lapi et al. ${ }^{24}$ reported that the removal of laboratory tests from the electronic request form can change ordering behaviour. Vidyarthi et al. ${ }^{25}$ targeted a range of ordering behaviours including teaching, social marketing, academic detailing, financial incentives and audit/feedback. They reported that laboratory ordering was reduced by $8 \%$ cumulatively over three years. Newman et al. ${ }^{26}$ also reported that a targeted education intervention substantially reduced the frequency of routine Ca testing, including in the ED setting. Removal of the ability to order all three electrolytes as a single order could also be considered.

This study has important limitations. As a single-centre study, the findings may not reflect practices in other EDs. In particular, our ED has electronic test ordering, which may increase the ease of ordering tests. This phenomenon has been observed in other settings. ${ }^{27}$ Additionally, our electronic system allows ordering of these electrolytes as a coupled package as well as individual ordering. We defined an abnormal electrolyte level as one 
outside of our laboratory reference range. It is likely that levels just outside of the range have little clinical significance and are not truly abnormal. However, our definition was deliberate as we aimed to examine management change among all patients, including those with marginally abnormal and normal levels. The retrospective study design precluded the opportunity to determine the rationale behind management changes, especially in the setting of normal electrolyte levels. We did not examine whether to the ED test results affected a change in patient management after admission to the ward. Hence, the overall management change may have been an under-estimate. Finally, the cost of the testing, based on the Medicare Benefits Schedule ${ }^{6}$, may have lacked accuracy and the true cost to the ED is unknown.

This article is protected by copyright. All rights reserved. 


\section{CONCLUSION}

While $\mathrm{Ca}, \mathrm{Mg}$ and $\mathrm{PO}_{4}$ testing in the $\mathrm{ED}$ is common, the yield of clinically significant abnormal levels is low and patient management is rarely changed. Testing of these electrolytes needs to be rationalised to avoid over testing and resource utilisation. The reasons why some patients with normal electrolyte levels have management change needs to be determined. Further study is also recommended to determine the characteristics of ED patients at risk of abnormal electrolyte levels. The findings will inform educational initiatives and clinical guidelines aimed at rationalizing $\mathrm{Ca}, \mathrm{Mg}$ and $\mathrm{PO}_{4}$ testing.

This article is protected by copyright. All rights reserved. 


\section{ACKNOWLEDGEMENTS}

nil

This article is protected by copyright. All rights reserved. 


\section{REFERENCES}

1. Levinson W, Kallewaard M, Bhatia RS, Wolfson D, Shortt S, Kerr EA. 'Choosing Wisely’: a growing international campaign. BMJ Qual Saf 2015; 24: 167-74

2. Lindner RA. Choosing Wisely Australia: changing behaviour in health care. Med J Austral 2018; 208: 105-6

3. Sah S, Elias P, Ariely D. Investigation momentum: the relentless pursuit to resolve uncertainty. JAMA Intern Med 2013; 173: 932-3

4. National Prescribing Service MedicineWise. Choosing Wisely Australia. Available from: http://www.choosingwisely.org.au/home (Last accessed March 4, 2019)

5. Rose WD, Martin JE, Abraham FM, Jackson RL, Williams JM, Gunel E. Calcium, magnesium, and phosphorus: emergency department testing yield. Acad Emerg Med 1997; 4: $559-63$

6. Department of Health. Medicare Benefits Schedule Book Category 6 2017. Available from: http://www.mbsonline.gov.au/internet/mbsonline/publishing.nsf/Content/Downloads201707 (Last accessed March 4, 2019)

7. Chang WT, Radin B, McCurdy MT. Calcium, magnesium, and phosphate abnormalities in the emergency department. Emerg Med Clin North Am 2014; 32: 349-66

8. Weisinger JR, Bellorin-Font E. Magnesium and phosphorus. Lancet 1998; 352: 391-6

9. Fairley JL, Zhang L, Glassford NJ, Bellomo R. Magnesium status and magnesium therapy in cardiac surgery: A systematic review and meta-analysis focusing on arrhythmia prevention. J Crit Care 2017; 42: 69-77

This article is protected by copyright. All rights reserved. 
10. Arsenault KA, Yusuf AM, Crystal E et al. Interventions for preventing post-operative atrial fibrillation in patients undergoing heart surgery. Cochrane Database of Systematic Reviews 2013(1)

11. Kotecha D. Magnesium for Atrial Fibrillation, Myth or Magic? Circulation: Arrhythmia and Electrophysiology. 2016; 9: e004521

12. Ho KM, Sheridan DJ, Paterson T. Use of intravenous magnesium to treat acute onset atrial fibrillation: a meta-analysis. Heart 2007; 93: 1433-40

13. Rajagopalan B, Shah Z, Narasimha D et al. Efficacy of intravenous magnesium in facilitating cardioversion of atrial fibrillation. Circulation: Arrhythmia and Electrophysiology. 2016; 9: e003968.

14. De Baaij JH, Hoenderop JG, Bindels RJ. Magnesium in man: implications for health and disease. Physiol Rev 2015; 95: 1-46

15. Shiber JR, Mattu A. Serum phosphate abnormalities in the emergency department. $J$ Emerg Med 2002; 23: 395-400

16. Lindner G, Felber R, Schwarz C et al. Hypercalcemia in the ED: prevalence, etiology, and outcome. Am J Emerg Med 2013; 31: 657-60

17. Lee CT, Yang CC, Lam KK, Kung CT, Tsai CJ, Chen HC. Hypercalcemia in the emergency department. Am J Med Sci 2006; 331: 119-23

18. Stalnikowicz R. The significance of routine serum magnesium determination in the ED. Am J Emerg Med 2003; 21: 444-7

19. Stewart AF. Hypercalcemia associated with cancer. N Engl J Med 2005; 352: $373-9$.

This article is protected by copyright. All rights reserved. 
20. Liamis G, Rodenburg EM, Hofman A, et al. Electrolyte disorders in community subjects: prevalence and risk factors. Am J Med 2013; 126: 256-63

21. Silverberg SJ, Walker MD, Bilezikian JP. Asymptomatic primary hyperparathyroidism. $J$ Clin Densitom 2013; 16: 14-21

22. Lindner G, Funk GC, Leichtle AB et al. Impact of proton pump inhibitor use on magnesium homoeostasis: a cross-sectional study in a tertiary emergency department. Int $J$ Clin Pract 2014; 68: 1352-7

23. Geerse DA, Bindels AJ, Kuiper MA, et al. Treatment of hypophosphatemia in the intensive care unit: a review. Crit Care 2010; 14: R147

24. Lapi I, Juroa GF, Rako I, Rogi D. Changing the electronic request form proves to be an effective tool for optimizing laboratory test utilization in the emergency department. Int $J$ Med Inform 2017; 102: 29-34

25. Vidyarthi AR, Hamill T, Green AL, Rosenbluth G, Baron RB. Changing resident test ordering behavior: a multilevel intervention to decrease laboratory utilization at an academic medical center. Am J Med Qual 2015; 30: 81-7

26. Newman DB, Siontis KC, Chandrasekaran K, Jaffe AS, Kashiwagi DT. Intervention to reduce inappropriate ionized calcium ordering practices: a quality-improvement project. Perm J 2015; 19: 49-51

27. Petrou P. Failed attempts to reduce inappropriate laboratory utilization in an emergency department setting in Cyprus: Lessons learned. J Emerg Med 2016; 50: 510-7

This article is protected by copyright. All rights reserved. 


\section{Figure Legends:}

Figure 1. Patient flow through the study

Figure 2. Calcium test results and treatment given

Figure 3. Magnesium test results and treatment given

Figure 4. Phosphate test results and treatment given

This article is protected by copyright. All rights reserved. 


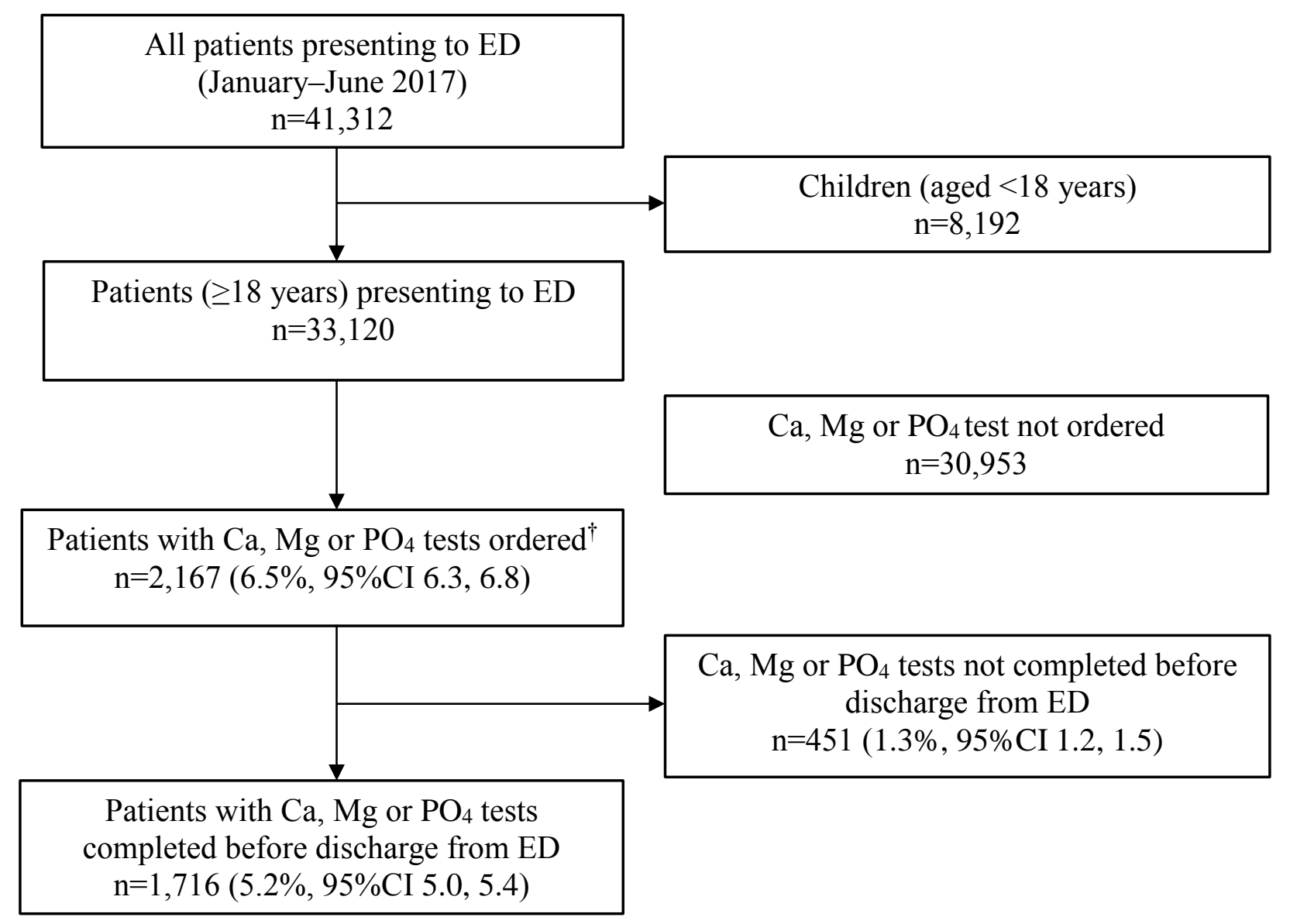

Ca Calcium, $\mathrm{Mg}$ Magnesium, $\mathrm{PO}_{4}$ Phosphate

${ }^{\dagger}$ one, two or all electrolyte tests may have been ordered 


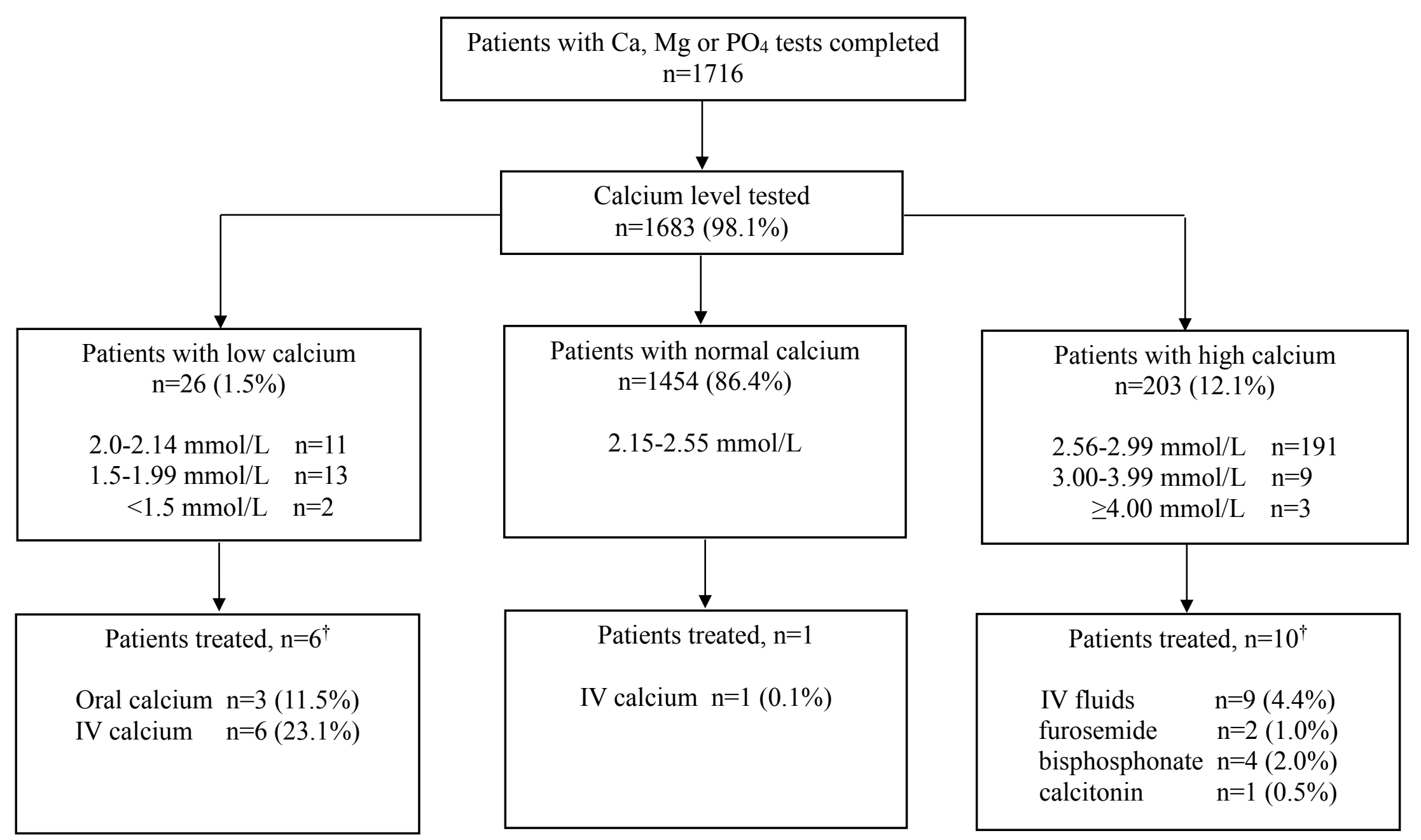

All percentages calculated using the patient number in the box immediately above $\dagger$ some patients received more than one treatment 


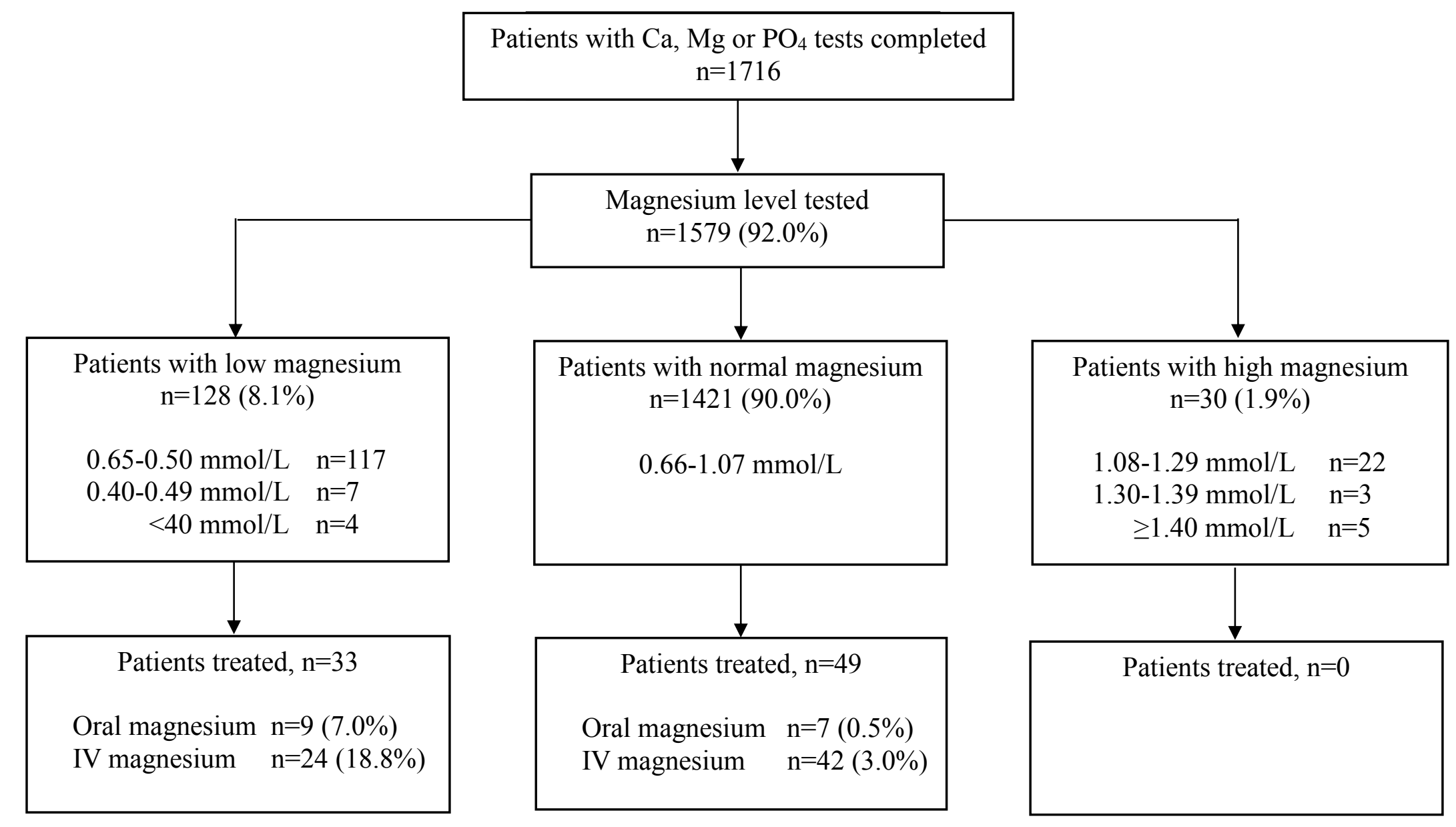

All percentages calculated using the patient number in the box immediately above

This article is protected by copyright. All rights reserved. 


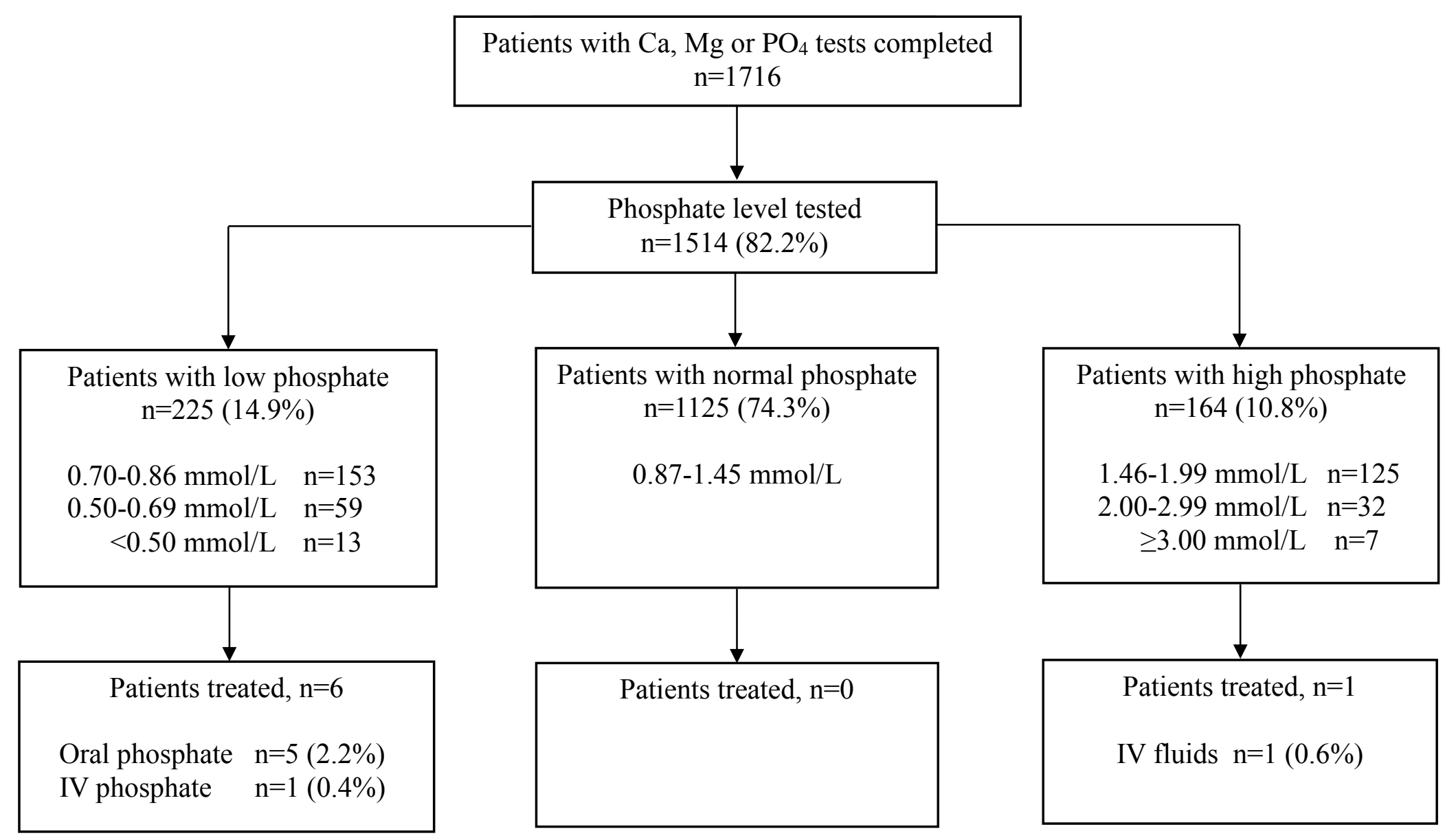

All percentages calculated using the patient number in the box immediately above 


\title{
Utility of calcium, magnesium and phosphate testing in the emergency department
}

\author{
(Calcium, Magnesium and Phosphate testing)
}

Patrick A Date BSci MD ${ }^{1}$

patrick.a.date@gmail.com

Jesse L Smith BSci MD ${ }^{2}$

jesse.lachlan.smith@gmail.com

William S Spencer BMedSci MD 3

Willsspencer1@gmail.com

Erik J de Tonnerre BMedSci MD ${ }^{4}$

edetonnerre@gmail.com

Michael J Yeoh MBBS FACEM ${ }^{5}$

Michael.Yeoh@austin.org.au

David McD Taylor MD DRCOG MPH FACEM ${ }^{6,7}$

David.Taylor@austin.org.au

${ }^{1}$ Intern, Austin Hospital, Studley Road, Heidelberg, Victoria, Australia

${ }^{2}$ Intern, Central Gippsland Health, Sale, Victoria, Australia

${ }^{3}$ Intern, Alfred Health, Commercial Road, Melbourne, Victoria, Australia

${ }^{4}$ Intern, Northern Sydney Local Health District, NSW Health, NSW

${ }^{5}$ Staff Specialist, Emergency Department, Austin Hospital, Studley Road, Heidelberg, Victoria, Australia

${ }^{6}$ Director of Emergency Medicine, Emergency Department, Austin Hospital, Studley Road, Heidelberg, Victoria, Australia

${ }^{7}$ Professor, Department of Medicine, University of Melbourne, Parkville, Victoria, Australia

\section{Corresponding Author:}

Professor David Taylor

Emergency Department, Austin Hospital

Studley Road, Heidelberg, Victoria, Australia 3084

Phone (W) +61 394964711

David.Taylor@austin.org.au

\section{Author Contributions:}

PD, MY and DT developed the protocol for the project that this research was drawn from. DT obtained ethics committee approval. PD, JS, WS and EdeT collected all the data. All authors assisted DT in data analysis and interpretation. All authors contributed to drafting and critical revision of the manuscript. DT supervised the project overall. All authors take responsibility for the manuscript.

Word count: 2500

This article is protected by copyright. All rights reserved. 


\section{University Library}

\section{- M M N E R VA A gateway to Melbourne's research publications}

Minerva Access is the Institutional Repository of The University of Melbourne

Author/s:

Date, PA;Smith, JL;Spencer, WS; de Tonnerre, EJ;Yeoh, MJ;Taylor, DM

Title:

Utility of calcium, magnesium and phosphate testing in the emergency department

Date:

2020-02-01

Citation:

Date, P. A., Smith, J. L., Spencer, W. S., de Tonnerre, E. J., Yeoh, M. J. \& Taylor, D. M. (2020). Utility of calcium, magnesium and phosphate testing in the emergency department. EMERGENCY MEDICINE AUSTRALASIA, 32 (1), pp.39-44. https:// doi.org/10.1111/1742-6723.13332.

Persistent Link:

http://hdl.handle.net/11343/285948 